\title{
Introduction to the World of Algorithmic Thinking
}

\author{
Barbara Strnad \\ Gimnazija Novo Mesto, Seidlova Cesta 9, 8000 Novo Mesto, Slovenija and Čarunalnik - Društvo Za Napredno Uporabo \\ Računalnikov, Ulica Talcev 3, Novo mesto, Slovenija
}

\begin{abstract}
In recent years, most developed societies have realized that it is very important for students to acquire the skill of algorithmic thinking and the basic knowledge of computer programming. Nowadays we have numerous ways that allow us to teach programming with appropriate first steps. The paper will present one of the possibilities which we have to introduce basic programming concepts to younger children-with Lego robots and a topic, who lives in a meadow?
\end{abstract}

Key words: Algorithmic thinking, Lego WeDo 2.0, programming, preschool children.

\section{Introduction}

In order for children to become active creators in computer science and informatics, it is necessary to learn the algorithmic way of thinking. Knowing the basic steps of programming is one of the best ways to do it. The purpose of this paper is to present a project we did in a kindergarten with Lego WeDo, which is a great tool to start introducing the world of programming to kids [1], and is practically suitable for all age groups. Most of the activities are based on a game and co-working. Lego robots allow us to do many cross-curricular links, including topics related to life, physical science, earth science and space technology.

\section{Cooperation with Preschool Children}

\subsection{Lego WeDo 2.0}

Lego ${ }^{\circledR}$ Education WeDo 2.0 [2] basic set (Fig. 1) is designed primarily for elementary school students, but we can also use it for working with preschool kids and high school students with no prior experience. The kit allows us to create and programme simple Lego ${ }^{\circledR}$ models. The set contains more than 280 items, including WeDo 2.0 Smart hub, one motor, a motion sensor that can detect objects at a distance of $15 \mathrm{~cm}$ and

Corresponding author: Barbara Strnad, professor, research fields: mathematics and computer science. a tilt sensor that can detect six different positions.

Smart hub is the electronic system, which is part of the product LPF (Lego ${ }^{\circledR}$ Power Functions) 2.0, a new technology platform for the program Lego $\AA$ Education.

It has a built-in low-energy Bluetooth technology that connects smart hub with software. Energy can be obtained via two AA batteries or rechargeable batteries. There are two I/O outputs, through which you can connect external motors, sensors or any of the other LPF 2.0 components. Built-in RGB light area can display 10 different colors, which can be controlled by software.

It is an excellent tool for introducing the basics of robotics and enabling interdisciplinary cooperation. It has the option of documenting and sharing. Programming is based on the principle of drag and drop.

\subsection{Starting the Activity}

We start with an exciting polygon, where children try to lead a live robot. First, we choose a volunteer and blindfold him. Then we place a dynamic polygon made of tables and chairs in the classroom, which enables them to securely lead "a live blindfolded robot" (Fig. 2). At first glance it may not be immediately apparent, but there are some programming concepts already hiding in the game. 


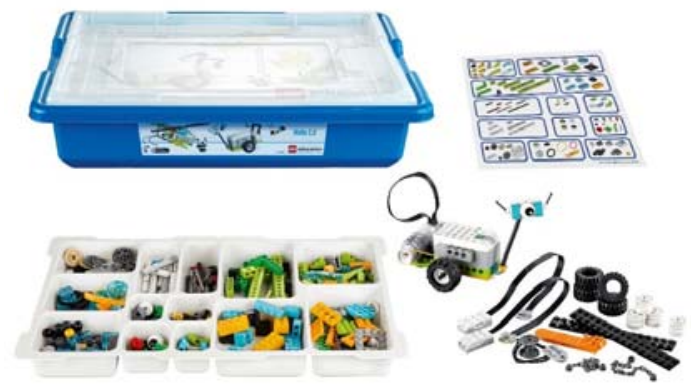

Fig. 1 Lego WeDo 2.0.

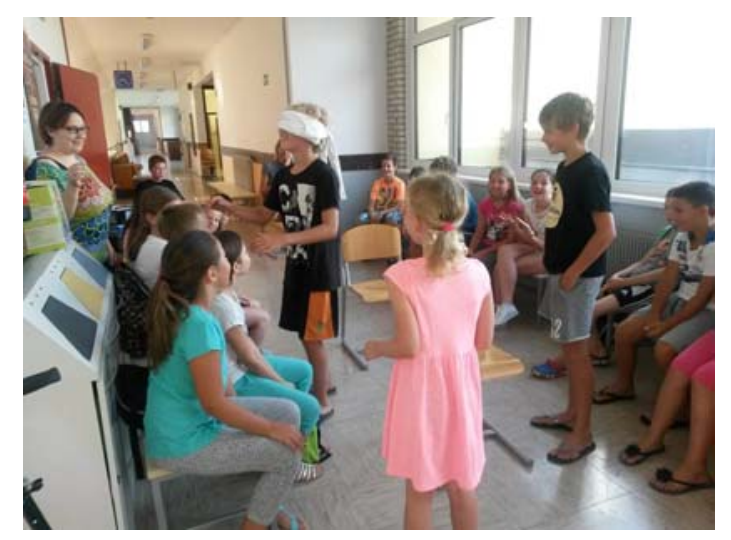

Fig. 2 Polygon.

The aim of the game is that the children learn from the experience what are the good and sufficient detailed instructions that enable successful and fast crossing of the polygon. Sometimes we can prepare a polygon in such a way that children can use the instructions in the loop or a conditional statement.

Children can see through this activity that some instructions are understood completely clear by some of them, while others may be misinterpreted and that there are also several procedures for the solution of polygons.

We further discuss how we perceive space when we are blindfolded and how our senses help us. Children usually figure out what is the connection between the robot and our game. An interesting topic is also to talk about the differences between robots and humans.

\subsection{Robots in Everyday Life}

We continue with a conversation about robots in everyday life. Children often say that they have not yet met a robot, but after some consideration they soon think of a robotic vacuum cleaner. They have already heard about or seen a robotic lawn mower or industrial robots. Then we talk about how we command the robots. The most thorough analysis of the robot's function can be carried out on a robotic vacuum cleaner that children know best. They know that robotic vacuum cleaner has a sensor for not falling which prevents falling down the stairs. Children can describe its moving really precisely. They know the cleaner uses a profiled rubber bumper to detect obstacles. They even know that it is necessary to lodge a border wire in areas where we do not want the robotic lawn mower to mow.

\subsection{Creating Our Own Robots}

Our robots, which we will build, will also require sensors for better orientation in space. We introduce two sensors in the kit, a tilt sensor and a motion sensor (Fig. 3).

It is time to build a robot and equip it with sensors. The focus is firstly on commands which will tell the robot how to move. We use printed command blocks on a bigger format. Children try to conclude what each command means just by observing the image (Fig. 4). Most children are very good at observing. They identify
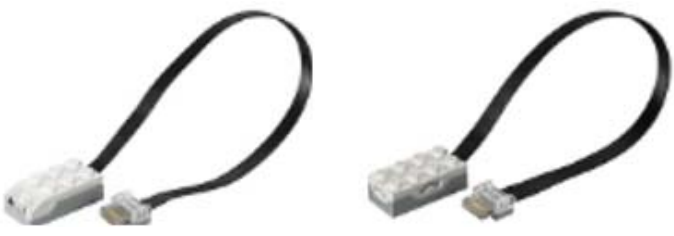

Fig. 3 Motion and tilt sensor.

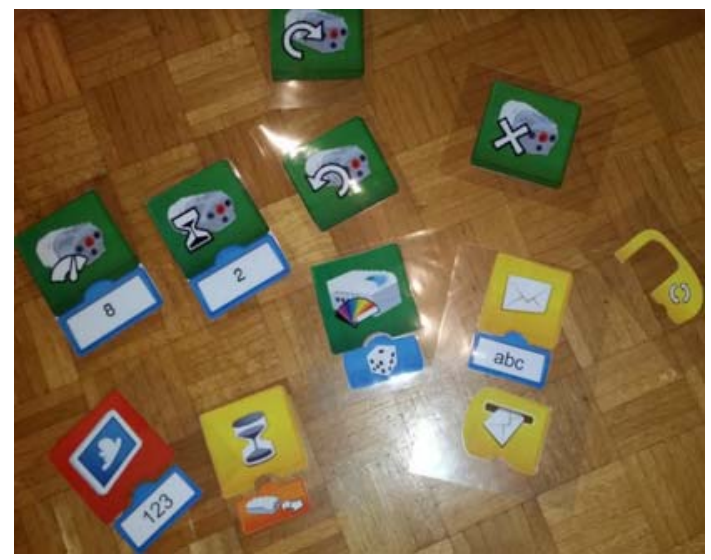

Fig. 4 Command blocks. 
a motor which rotates in the clockwise direction or in the opposite direction. They connect the engine with the hourglass and with the length of time that the motor will spin. They explain that the command block which determines the engine power shows the engine and power meter pointer.

We proceed with the assembly of Lego bricks. Following the instructions first robots are made and programmed to move, and then equipped with a motion sensor and a tilt sensor.

\section{Creativity of Preschool Children}

We had quite a few meetings with preschool children (Fig. 5), where we build different robots: a frog, a mantis, a spider, a caterpillar, a bee. Members of Čarunalnik were teaching children how to build correctly and follow the instructions and we did some basic programming.

First we started with the topic: Who lives in a meadow? We divided the children into six groups, each group picked one animal-bee, spider, snake, caterpillar, mantis, and firefly. There were four children in each group. Two groups worked on a robot, while the other two groups worked on modeling an animal's environment, a meadow with a pond (Fig. 6). The last two groups learned about a chosen animal, explored how they live, how bees take an active role in plant reproduction, they researched different stages in the life circle of a frog, butterfly. Groups rotated on each session.

Before visiting the kindergarten, we elected all needed bricks for creating a specific robot, so the children did not spend too much time searching, and they did not lose interest in searching among too many bricks. Group members that were constructing and building robots had different tasks: they had to find the right bricks, one had to put the next page of instructions on the tablet, and another had to check if pieces were joined correctly. The children did all of the tasks alternately, except the search for needed parts, which was everybody's job. They built alternately; some children had more experience following instructions and better spatial performance. They helped children with more difficulties and they were "supervisors".

Once we constructed the robot, we wrote simple programs, where animals were moving forward and backward, they were making different sounds and the RGB light surface on Smart Hub changed colors. The children then tried to modify programs.

Because of a major interest and enthusiasm among the children, we added two more topics: jungle, and working machines and heavy-equipment vehicle (Fig. 7).

We experienced major progress in following building instructions, better spatial performance, and better motoric skills when putting bricks together. The children were excited and they happily presented their work to other kindergarten groups and their parents.

The reactions to the project we did together were extremely positive. Children were satisfied, because they really assembled their own robot, wrote a program and created an environment for the robot-animal
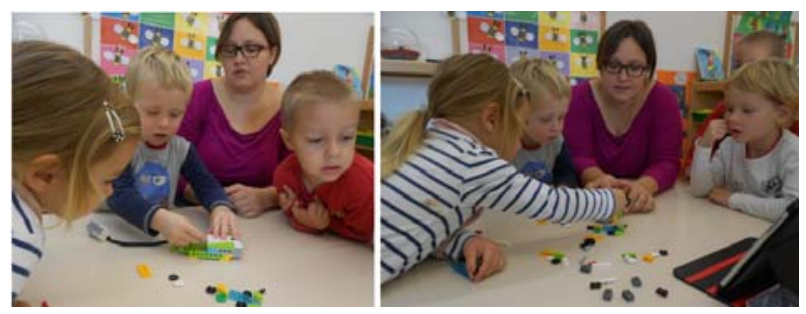

Fig. 5 Building robot with preschool children.

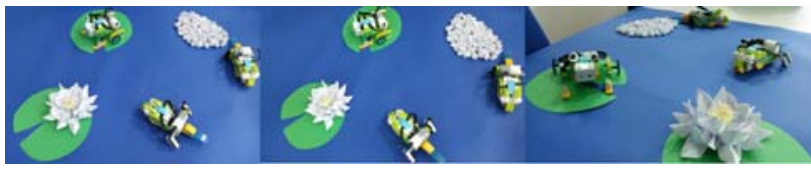

Fig. 6 Our frog-robots in a pond.

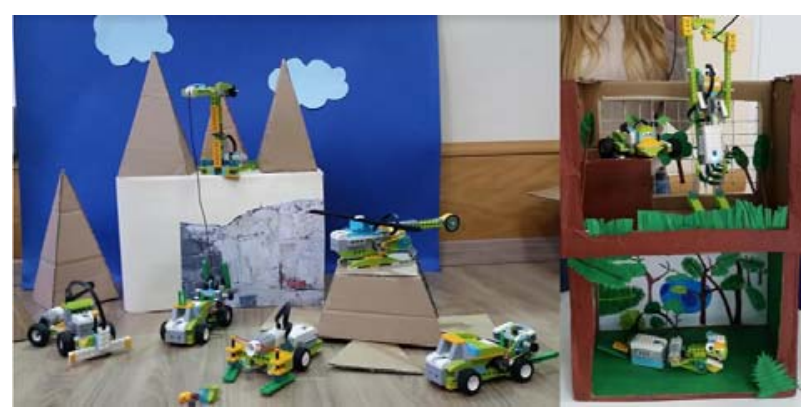

Fig. 7 Robots in their environment. 
in the meadow. Meanwhile they visited some interesting experts. They visited a beekeeper and they molded their own wax candles. Children learned a lot about animals in the meadow. They were able to use their imagination and creativity. Children enjoyed in the implementation of their own ideas and comparing their products. After completing the project, the children were excited and eager for new meetings.

\section{Conclusion}

Panellists on computer literacy in primary schools this year agreed that the school system is in urgent need of change in the field of computer skills, because without these skills, students will not be competitive in almost any field of expertise. There is almost no activity associated with digitization, so computer skills are vital.

We introduce children to the world of programming and algorithmic thinking through attractive robotics by programming small robots. In this way there is a connection between the mind maps and the physical world. Learning about computer concepts and developing procedural way of thinking help students acquire knowledge and skills that are much more durable than the rapidly evolving technology.

\section{References}

[1] Fisher, C. R. 2014. "Key-Stage Computing: Evaluating the Suitability of Lego Mindstorms NXT 2.0 for Use in Early Computer Science Education.” Discovery, Invention \& Application, University of Derby.

[2] LEGO. Lego WeDo 2.0. 2016, January 2. Retrieved from https://education.lego.com/en-us/products/wedo-2-0-core -set-software-and-get-started-project/45300. 